\title{
Peran Teacher Structure terhadap Engagement melalui Academic Buoyancy pada Siswa Menengah Atas
}

\author{
Surya Cahyadi dan Meilani Rohinsa \\ Universitas Padjadjaran Bandung
}

\begin{abstract}
The current research aims to investigate whether students' ability to deal with academic problems daily or academic buoyancy can mediate the effect of teacher structure in predicting senior high school students' engagement. The participant of the research consisted of 213 senior high school students (Female = 126; $59.2 \% ;$ Male $=87 ; 40.8 \%$ ). The age of participants' ranged between 15-18 years, with a mean of 15.41 $(S D=0.53)$. The instrument in the current research included Teacher Structure Questionnaire, Academic Buoyancy Scale, and Engagement Questionnaire. Data analysis was conducted using multiple regression tests. Based on research findings, Academic buoyancy mediates the effect of teacher structure in predicting senior high school students' engagement. The findings of the study were discussed under the light of relevant literature, and some suggestions were made for future research. This finding implies that teachers need to be aware that every student needs the ability to deal with everyday academic problems in school. The existence of teacher structure can fulfill this ability. This support will shape students' engagement with learning activities in the classroom.
\end{abstract}

Keyword: Academic buoyancy; Engagement; Teacher Support

\begin{abstract}
Abstrak
Penelitian ini bertujuan untuk menginvestigasi apakah pengaruh teacher structure terhadap engagement dapat dimediasi oleh kemampuan siswa mengatasi masalah atau yang dikenal dengan academic buoyancy. Dalam penelitian ini melibatkan 213 siswa SMA (Wanita= 126; 59.2\%; Pria $=87 ; 40.8 \%$ ) sebagai responden. Usia responden dalam penelitian ini berkisar antara 15-18 tahun dengan mean $=15.41$ ( $\mathrm{SD}=0.53$ ). Alat ukur yang digunakan dalam penelitian ini adalah kuesioner Teacher Structure, Academic Buoyancy Scale dan Engagement. Data dianalisis dengan menggunakan uji regresi berganda. Hasil penelitian menunjukkan bahwa academic buoyancy terbukti dapat memediasi pengaruh teacher structure terhadap engagement. Implikasi dari hasil ini adalah para guru perlu menyadari bahwa setiap siswa memerlukan academic buoyancy dan hal ini dapat dipenuhi oleh adanya dukungan guru berupa teacher structure dan academic buoyancy akan engagement siswa terhadap aktivitas belajar di kelas.
\end{abstract}

Kata kunci: Academic buoyancy; Engagement; Teacher Support

Pendidikan memiliki peranan yang penting dalam upaya peningkatan sumber daya manusia ke arah yang lebih baik. Tujuan pendidikan formal akan tercapai apabila siswa 
terlibat dalam aktivitas pembelajaran yang dirancang oleh para guru dengan merujuk pada kurikulum yang mendasarinya. Keterlibatan siswa terhadap berbagai aktivitas di sekolah dikenal dengan 'student engagement', 'academic engagment', 'school engagement' atau 'engagement'. Untuk selanjutnya dalam penelitian ini akan digunakan istilah engagement. Engagement didefinisikan sebagai suatu kondisi dimana terdapatnya keterlibatan perilaku yang berkelajutan dalam aktivitas belajar yang disertai dengan nada emosi yang positif (Skinner \& Belmont, 1993).

Engagement bukan saja diperlukan agar siswa dapat menguasai keterampilan ataupun kemampuan yang diajarkan di sekolah, engagement juga diperlukan agar siswa dapat beradaptasi dengan tuntutan pendidikannya (Connell \& Wellborn, 1991). Dengan siswa engage terhadap kegiatan belajarnya, siswa akan semakin terdorong untuk belajar dan semakin ingin mengasah keterampilan yang dibutuhkan untuk sukses di sekolah (Lawson \& Lawson, 2013). Dari berbagai penelitian yang telah ada juga dapat disimpulkan bahwa engagement adalah faktor yang penting bagi learning dan academic achievement (Finn \& Zimmer, 2012).

Pentingnya engagement siswa terhadap sekolah telah diakui oleh para guru dan peneliti di bidang pendidikan. Furlong \& Christenson (2008) menyatakan bahwa konstruk engagement siswa di sekolah merupakan konstruk yang relevan bagi semua siswa, tanpa terkecuali. Artinya, apapun jenjang pendidikan yang sedang ditempuh siswa, dimanapun siswa bersekolah, atau apapun kurikulum yang diterapkan pada siswa, semua siswa pasti membutuhkan engagement terhadap aktivitas belajarnya untuk mencapai hasil-hasil pendidikan yang diharapkan.

Engagement sangat dibutuhkan terutama pada saat memasuki jenjang Sekolah Menengah Atas (SMA). Memasuki jenjang SMA, siswa berada pada tahap remaja dimana memiliki tuntutan yang lebih besar mengambil tindakan yang tepat dalam pilihan pendidikannya. Selain itu selama masa SMA, kemampuan dan keterampilan siswa juga semakin diasah untuk siap masuk dalam lingkup kehidupan yang lebih luas yaitu di perguruan tinggi maupun lingkup pekerjaan itu, siswa SMA perlu engage terhadap proses pendidikan di sekolah.

Sampai dengan saat ini Engagement dianggap bukanlah merupakan suatu trait yang sudah pasti. Engagement dianggap sebagai suatu kondisi yang dapat di bentuk oleh lingkungan 
(Fredricks, Blumenfeld, \& Paris, 2004b). Dalam berbagai literatur salah satu patner sosial yang yang dianggap paling signifikan dalam mengembangkan engagement siswa adalah guru (Skinner \& Pitzer, 2012). Siswa menghabiskan sebagian besar waktunya di sekolah, terutama di kelas. Interaksi siswa dengan guru di kelas dapat dikatakan sebagai sesuatu yang paling dekat dan secara potensial dapat memengaruhi engagement siswa (Newmann, King, \& Youngs, 2005).

Salah satu bentuk dukungan guru yang dapat memengaruhi engagement siswa adalah structure dari guru (Deci \& Ryan, 2017; Connell \& Wellborn, 1991). Teacher structure merupakan salah satu dimensi dukungan dari guru dalam teori motivasi yaitu self determination theory.

Guru dapat memfasilitasi structure yang jelas di kelas, dengan cara menyampaikan apa yang harus dicapai siswa dalam suatu aktivitas belajar, misalnya dengan menyampaikan indikator penilaian dari suatu tugas. Guru memperhatikan kemampuan siswa dalam menyampaikan suatu materi, dengan tujuan agar siswa lebih mudah menguasainya. Apabila siswa belum dapat menguasai suatu materi, guru memberikan umpan balik yang sifatnya informasional kepada siswa tersebut (Connell \& Wellborn, 1991). Structure juga dapat difasilitasi dengan guru memastikan siswa mengetahui aturan di kelasnya, dan guru juga menerapkan aturan tersebut dengan konsisten.

Teacher structure merupakan salah satu strategi yang penting yang dapat memfasilitasi siswa untuk mencapai keberhasilan di sekolah. Structure guru dapat membuat siswa mencapai kesuksesan dan menghindari kegagalan dalam bidang akademik. Hal ini telah terbukti melalui penelitian Skinner, Johnson, Snyder (2005) yang menyatakan terdapat hubungan structure dangan engagement.

Di dekade ini, penelitian menganai engagement sendiri mulai berubah tujuannya. Saat ini engagement dianggap penting bukan sekedar agar siswa dapat tetap bertahan di sekolah, namun telah bergeser menjadi sesuatu yang diperlukan agar siswa dapat memenuhi tuntutan akademik di sekolah (Christension, Sinclair, Lehr and Godber, 2001). Hal ini dikarenakan kesuksesan siswa dalam menyelesaikan sekolah tidak hanya ditandai dengan siswa yang sekedar tetap bertahan di sekolah, namun apakah siswa mampu mengatasi tantangan, tuntutan akademis sehari-hari di sekolah. 
Setiap siswa di sekolah tanpa kecuali, pasti pernah mengalami kemunduran akademik dan tantangan yang tipikal dengan kondisi sehari hari di sekolah (misalnya dalam menghadapi nilai yang rendah, menyelesaikan tugas, mengatasi tekanan ulangan dan tugas yang sulit) (Martin \& Marsh, 2007). Pada masa remaja juga terbukti terjadi penurunan engagement yang pada umumnya dikarenakan bertambahnya tuntutan akademis selama mereka menjalani pendidikan di sekolah menengah (Eccles et al, 1993). Hal ini sejalan dengan pernyataan dari Newman \& Newman (2009) bahwa academic expectation akan berubah menjadi lebih kompleks dan siswa akan lebih bertambah tanggung jawabnya pada saat siswa menjalani pendidikan di sekolah menengah.

Tantangan yang dialami siswa dalam proses belajar dapat digolongkan sebagai everyday hassles atau tekanan akademis yang yang biasa dialami siswa dalam kesehariannya (Martin \& Marsh, 2009). Oleh karena itu diperlukan suatu kemampuan untuk menghadapi atau bernegosiasi dengan hal tersebut. Martin dan Marsh (2013) menyatakan bahwa diperlukan Academic Buoyancy atau kemampuan dalam diri siswa untuk menghadapi tantangan akademis sehari-hari dan sifatnya tidak parah. Academic Buoyancy didefinisikan sebagai kemampuan siswa untuk mengatasi kemunduran akademik ataupun tantangan yang lazimnya di hadapi di sekolah (Martin \&Marsh, 2008).

Beberapa penelitian yang telah di lakukan menunjukkan bahwa masalah dan tantangan yang sehari-hari di hadapi siswa remaja di sekolah menengah dapat mempengaruhi level engagement siswa terhadap sekolah (Skinner \& Pitzer, 2012). Dibutuhkan kemampuan siswa untuk mengatasi masalah dan tantangan akademis sehari-hari atau academic buoyancy, agar siswa dapat tetap terlibat atau engage dengan aktivitas belajar di kelas (Martin \& Marsh, 2007).

Hubungan guru dan siswa, atau dukungan yang diberikan guru terhadap siswanya adalah salah satu faktor yang dapat memengaruhi academic buoyancy seseorang (Martin \& Marsh, 2009). Teacher structure yang merupakan salah satu bentuk dukungan yang diberikan oleh guru dapat membuat siswa memiliki perasaan bahwa dirinya memiliki kendali (sense of control) serta memiliki belief bahwa dirinya memiliki sesuatu yang diperlukan untuk mencapai keberhasilan di sekolah (sense of competence). 
Siswa yang memiliki sense of control merasa dirinya mampu mengendalikan hasil akademiknya di masa yang akan datang. Siswa yang memiliki sense of control mempersepsikan hasil akademiknya yang telah dicapainya adalah dampak dari penyebab internal (disebabkan oleh sesuatu yang berasal dari dalam dirinya sendiri) dan hasil akademik tersebut dapat dikendalikan oleh tindakan dirinya (Weiner, 2010; Skinner, Zimmer Gembeck \& Connell, 1998). Sehingga pada saat siswa menghadapi tuntutan akademis sehari-hari (everyday hassless), mereka menilai hal tersebut sebagai sesuatu yang dapat dikendalikan oleh dirinya sendiri (misalnya siswa menganggap kemunduran akademik yang dialaminya dikarenakan dirinya kurang belajar) sehingga mereka cenderung akan mengubah penyebabnya, dengan cara mencari penyelesaian masalah yang untuk mengatasi everyday hasless yang dihadapinya (misalnya dengan belajar lebih tekun lagi di waktu-waktu yang selanjutnya, untuk menghindari terulangnya hal yang sama). Penyelesaian masalah siswa yang terfokus pada masalah ini dapat membuat siswa mengatasi everyday hassless yang dialaminya di sekolah atau yang disebut memiliki academic buoyancy.

Academic buoyancy juga secara positif berhubungan dengan dengan engagement. Data dari penelitian longitudinal menunjukkan bahwa siswa yang menghayati dirinya tidak dapat mengatasi tantangan ada kemunduran di sekolah (memiliki academic buoyancy yang rendah) maka akan memiliki level engagement yang rendah, motivasi belajar yang rendah dan performance yang rendah (Martin \& Marsh, 2017).

Sejauh pengetahuan peneliti sampai dengan saat ini masih sangat terbatas penelitian empiris yang membuktikan teacher structure dapat memengaruhi engagement seorang siswa. Selain itu masih terbatas pula penelitian empiris yang membuktikan teacher structure dapat memengaruhi academic buoyancy, dan academic buoyancy dalam memengaruhi engagement seorang siswa. Oleh karena itu tujuan dari penelitian ini adalah untuk membuktikan bagaimana Teacher structure sebagai faktor yang dapat mempengaruhi academic buoyancy, dan selanjutnya academic buoyancy akan mempengaruhi engagement siswa terhadap aktivitas akademiknya. Oleh karena itu pertanyaan dalam penelitian ini adalah apakah academic buoyancy memediasi pengaruh Teacher structure terhadap engagement, pada siswa SMA di Bandung. Adapun Hipotesa yang akan diuji dalam penelitian ini adalah : 1) Academic buoyancy memediasi 
pengaruh Teacher structure terhadap engagement, 2) Teacher structure memiliki pengaruh yang signifikan positif dengan engagement, 3) Teacher structure memiliki pengaruh yang signifikan dengan academic buoyancy, 4) Academic buoyancy memiliki pengaruh yang signifikan positif dengan engagement.

\section{Metode}

Jenis penelitian ini adalah desain korelasional. Penelitian ini akan menguji hubungan antara variabel eksogen yaituteacher structure, variabel endogen yaitu engagement dan academic buoyancy sebagai variabel mediator. Populasi penelitian ini adalah siswa yang suatu SMA di Bandung, pada tahun ajaran 2018/2019.

Teacher Structure diukur menggunakan kuesioner Teacher structure dari Skinner dan Belmont (1993). Alat ukur ini terdiri dari 29 item yang mengukur persepsi siswa mengenai apakah guru mereka menjelaskan bagaimana harapan guru terhadap perilaku siswa, apakah guru memberikan kejelasan dan konsisten dalam menerapkan konsekuensi dari perilaku siswa (contoh: "setiap kali saya melakukan sesuatu yang salah, guru saya bertindak berbeda"). Tersedia empat pilihan jawaban yaitu Tidak Sesuai (TS), Kurang Sesuai (KS), Cukup Sesuai (CS), dan Sangat Sesuai (SS). Konsistensi internal, diukur menggunakan Alpha Cronbach, yaitu 0.79 yang dapat di kategorikan sebagai high reliability (DeVellis, 1991).

Academic Buoyancy diukur dengan menggunakan kuesioner Academic Buoyancy Scale (ABS, Martin dan Marsh, 2008), yang terdiri dari 4 item mengenai persepsi siswa kemampuannya mengatasi masalah akademis sehari-hari di sekolah (contoh "saya tidak akan membiarkan stress akademik menguasai saya" ). Tersedia empat pilihan jawaban yaitu Tidak Sesuai (TS), Kurang Sesuai (KS), Cukup Sesuai (CS), dan Sangat Sesuai (SS). Konsistensi internal, diukur menggunakan Alpha Cronbach, yaitu 0.80 yang dapat dikategorikan respectable (DeVellis, 1991).

Engagement diukur dengan menggunakan kuesioner Engagement dari Skinner et al (2009). Alat ukur ini terdiri dari 25 item yang mengukur engagement siswa terhadap aktivitas belajar di kelas (contoh: "saya bekerja keras pada saat saya memulai sesuatu yang baru di kelas" ). Tersedia empat pilihan jawaban yaitu Tidak Sesuai (TS), Kurang Sesuai (KS), Cukup 
Sesuai (CS), dan Sangat Sesuai (SS). Kuesioner asli yang berbahasa Inggis telah di translate ke dalam bahasa Indonesia oleh penulis pertama (Meilani) dan telah di cek oleh ahli bahasa Inggris. Konsistensi internal, diukur menggunakan Alpha Cronbach, yaitu 0.78 yang dapat dikategorikan respectable (DeVellis, 1991).

\section{Hasil}

Seluruhnya terdapat 213 responden yang digunakan dalam penelitian ini. Usia rata rata dari masing-masing responden 15.41 tahun $(\mathrm{SD}=0,51$, dengan rentang usia 14-18 tahun). Wanita $=126(59.2 \%)$ dan Laki-laki $=87(40.8 \%)$. Sebelum melakukan uji regresi, telah dilakukan uji asumsi klasik untuk memastikan bahwa data yang diteliti telah berdistribusi normal, tidak menunjukkan gejala heteroskedastisitas, dan tidak menunjukkan gejala multikolinearitas. Berdasarkan uji yang telah dilakukan maka diasumsikan bahwa data dalam penelitian ini telah memenuhi syarat untuk diterapkan dalam metoda analisis regresi.

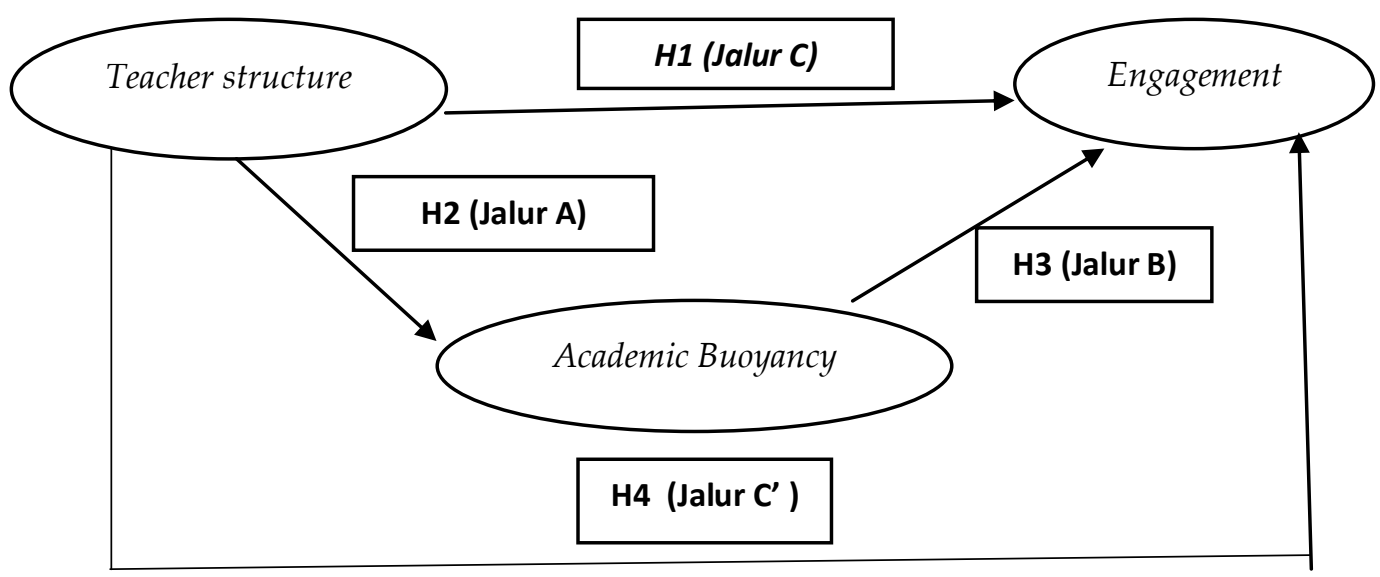

Gambar 1

Skema penelitian

Tabel 1

Uji Regresi antara Teacher Structure dan Engagement

\begin{tabular}{|c|c|c|c|c|c|}
\hline \multirow[t]{2}{*}{ Model } & \multicolumn{2}{|c|}{$\begin{array}{l}\text { Unstandardized } \\
\text { Coefficients }\end{array}$} & \multirow{2}{*}{$\begin{array}{l}\text { Standardized } \\
\text { Coefficients } \\
\text { (B) }\end{array}$} & \multirow[t]{2}{*}{$\mathrm{t}$} & \multirow[t]{2}{*}{ Sig. } \\
\hline & B & Sdt. error & & & \\
\hline \multirow{2}{*}{$\begin{array}{l}\text { Teacher } \\
\text { structure }\end{array}$} & 47.361 & 2.897 & .192 & 19.177 & .000 \\
\hline & .273 & .108 & & 2.341 & 0.016 \\
\hline
\end{tabular}


Berdasarkan data yang ditunjukkan oleh Tabel 1 menunjukkan $ß=0.192$ dengan sig $=$ 0,016 ( $\mathrm{p}<0.05)$. Hal ini menunjukkan terdapat hubungan yang positif namun termasuk dalam kriteria yang sangat lemah (menurut kriteria Sarwono, 2006) antara teacher structure dan engagement. Teacher structure diasumsikan dapat memprediksi munculnya engagement.

Tabel 2

Uji Regresi antara Teacher Structure dan Academic Buoyancy

\begin{tabular}{llllll}
\hline Model & \multicolumn{2}{l}{$\begin{array}{l}\text { Unstandardized } \\
\text { Coefficients }\end{array}$} & $\begin{array}{l}\text { Standardized } \\
\text { Coefficients } \\
\text { (B) }\end{array}$ & $\mathrm{t}$ & Sig. \\
\cline { 2 - 5 } & $\mathrm{B}$ & Sdt.error & $(3302$ & 13.437 & .000 \\
\hline Teacher structure & 17.105 & 1.256 & .302 & & \\
& .201 & .083 & & 4.383 & 0.00 \\
\hline
\end{tabular}

Berdasarkan data yang ditunjukkan oleh Tabel 2 menunjukkan $ß=0.308$ dengan sig = 0,000 ( $\mathrm{p}<0.05)$. Hal ini menunjukkan terdapat hubungan yang positif yang cukup kuat (menurut kriteria Sarwono, 2006) antara teacher structure dan academic buoyancy. Teacher structure diasumsikan dapat memprediksi munculnya academic buoyancy.

Tabel 3

Uji Regresi antara Academic Buoyancy dan Engagement

\begin{tabular}{llllll}
\hline Model & \multicolumn{2}{l}{$\begin{array}{l}\text { Unstandardized } \\
\text { Coefficients }\end{array}$} & $\begin{array}{l}\text { Standardized } \\
\text { Coefficients } \\
(ß)\end{array}$ & $\mathrm{t}$ & Sig. \\
\cline { 2 - 5 } & $\mathrm{B}$ & Sdt. error & .259 & 12.847 & .000 \\
\hline $\begin{array}{l}\text { Dukungan } \\
\text { Guru }\end{array}$ & 37.489 & 3.874 & & 3.281 & 0.001 \\
\hline
\end{tabular}

Tabel 3 menunjukkan $ß=0.59$ dengan sig $=0,001(p<0.05)$. Hal ini menunjukkan terdapat hubungan yang positif yang cukup kuat (menurut kriteria Sarwono, 2006) antara academic buoyancy dan engagement. Academic buoyancy diasumsikan dapat memprediksi munculnya Engagement.

Tabel 4

Uji Regresi Berganda antara Teacher Structure, Academic Buoyancy dan Engagement

\begin{tabular}{lllll}
\hline Model & $\begin{array}{l}\text { Unstandardized } \\
\text { Coefficients }\end{array}$ & $\begin{array}{l}\text { Standardized } \\
\text { Coefficients }\end{array}$ & Sig. \\
\hline
\end{tabular}




\begin{tabular}{llllll}
\hline & $\mathrm{B}$ & Sdt. error & $(\mathrm{B})$ & & \\
\hline Teacher & 42.675 & 3.846 & & 11.652 & .000 \\
structure & .193 & .121 & .165 & 1.903 & 0.9 \\
& & & & 5 & 5 \\
Academic & .418 & .187 & .189 & 2.325 & .017 \\
buoyancy & & & & & \\
\hline
\end{tabular}

Data diatas menunjukkan Direct effect (jalur c) koefisen regresinya turun dari 0.273 (Tabel 1) menjadi 0.193 (Tabel 4). Hal ini menunjukkan bahwa hubungan Teacher structure dan Engagement dapat dimediasi oleh Academic Buoyancy. Berdasarkan nilai standardized coefficient dari kedua variabel tersebut $\beta=0.165$, dapat dilihat bahwa hubungan kedua variabel itu tetap positif. Hal lain yang dapat dilihat dari data di atas adalah hubungan langsung antar kedua variabel tersebut menunjukkan p yang lebih besar dari 0.05 yakni sebesar 0.095, sehingga menurut Baron dan Kenny (1998) terjadi full mediation dalam penelitian ini.

\section{Pembahasan}

Berdasarkan hasil analisis terhadap data yang ada, ditemukan bahwa academic buoyancy dapat memediasi pengaruh teacher structure terhadap engagement siswa Sekolah Menengah Atas. Dalam penelitian ini, hasil perhitungan direct effect teacher stucture terhadap engagement memiliki koefisien korelasi sebesar 0.165 (tabel. 4). Dalam penelitian ini juga terdapat penurunan koefisien regresi dari 0.273 (tabel 1) menjadi 0.193 (tabel 4). Bedasarkan data tersebut dapat disimpulkan bahwa academic buoyancy dapat memediasi pengaruh teacher structure dan engagement. Hal ini membuktikan bahwa hipotesis pertama yang diajukan oleh peneliti dapat diterima.

Hasil analisis data menunjukkan bahwa korelasi antara teacher structure dan engagement temasuk dalam kategori lemah, namun korelasi ini dapat dimediasi oleh academic buoyancy. Artinya semakin siswa menghayati bahwa gurunya menyampaikan dengan jelas apa yang harus dicapai siswa dalam belajar, gurunya menentukan target belajar yang bersifat moderat dan target yang ditetapkan oleh guru tersebut telah mempertimbangkan kemampuan siswa. Selain itu siswa juga menghayati bahwa guru juga memperhatikan kemampuan siswa dalam 
menyampaikan suatu materi, guru menerapkan aturan dengan konsisten dan siswa menghayati bahwa gurunya bersedia memberikan umpan balik yang sifatnya informasional mengenai bagaimana siswa mencapainya maka siswa akan mempersepsi bahwa dirinya memiliki kemampuan mengatasi masalah-masalah akademis sehari- hari di sekolah atau memiliki academic buoyancy. Dengan memiliki academic buoyancy maka siswa dapat berhasil menyelesaikan everyday hassles atau masalah-masalah akademik yang sehari-hari dihadapinya di sekolah dengan cara konstruktif. Keberhasilan mereka menyelesaikan everyday hassles ini akan meningkatkan self esteem siswa dan membuat siswa menjadi engage terhadap aktivitas belajar di kelas (Martin \& Marsh 2006, 2008, Miller et al 2013).

Hasil ini memberikan dukungan terhadap konsep yang dikemukakan oleh Martin dan Marsh (2009) bahwa faktor hubungan guru dan siswa, yang dalam penelitian ini adalah teacher structure merupakan salah satu faktor yang memengaruhi academic buoyancy. Hasil penelitian ini juga memberikan dukungan pada konsep dari Martin dan Marsh (2007) yang menyatakan bahwa diperlukan academic buoyancy agar siswa dapat engage terhadap aktivitas belajar di kelas.

Dalam penelitian ini ditemukan bahwa terdapat korelasi yang positif dalam kategori yang sangat lemah antara teacher structure dan engagement. Berarti hal ini membuktikan bahwa hipotesis kedua yang diajukan oleh peneliti dapat diterima. Perlakukan yang terstruktur dari guru, misalnya dengan adanya kejelasan dan kekonsistenan dalam apa yang harus dicapai siswa dan aturan yang harus diikuti siswa, hal ini membuat siswa menganggap lingkungannya menjadi suatu tempat yang yang aman dan dapat diprediksi (Bandura, 1977; Skinner et al, 1988). Target yang sifatnya moderat yang harus dicapai siswa serta adanya aturan yang diterapkan secara konsisten, maka akan membuat siswa menganggap suatu aktivitas menjadi sesuatu yang menantang (Niemic \& Ryan, 2009), dan dengan adanya umpan balik yang sifatnya informasional, maka akan membuat siswa menghayati bahwa dirinya memiliki dukungan yang adekuat untuk mencapainya (Niemic \& Ryan, 2009). Tugas ataupun target yang disajikan dengan cara yang memudahkan siswa untuk memahaminya, maka akan membuat siswa merasa memiliki perasaan bahwa dirinya mampu untuk mencapainya. Secara kumulatif perasaan yang ditimbulkan oleh pengalaman-pengalaman yang terkait dengan struktuyang jelas ini akan membuat siswa merasa memiliki kemampuan menguasi apa yang 
diharapkan dari dirinya (Skinner, Zimmer Gembeck, \& Connell, 1989). Perasaan ini akan memberikan energi kepada siswa untuk berpartisipasi terhadap pada saat mengerjakan tugas yang berkaitan dengan aktivitas belajar di kelas (Baumeister \& Leary, 1995), dan juga perasaan positif terhadap aktivitas di kelasnya, seperti perasaan menikmati, senang dan bersemangat.

Hasil penelitian ini menunjukkan adanya korelasi positif yang termasuk cukup kuat dan signifikan antara variabel teacher structure dan academic buoyancy. Berarti berdasarkan hasil penelitian ini juga membuktikan hipotesis ketiga yang diajukan oleh peneliti, yaitu teacher structure terbukti secara signifikan berkorelasi dengan academic buoyancy. Hasil penelitian ini mendukung konsep yang diungkapkan oleh Martin dan Marsh (2009) hubungan guru dan siswa dapat memperngaruhi academic buoyancy siswa. Dimana, di dalam penelitian ini hubungan yang terbina dapat terbentuk melalui pemberian aturan ataupun harapan yang jelas serta bersedia memberikan dukungan instrumental maupun emosional terhadap siswanya. Hal ini akan membuat siswa lebih dapat mengatasi hambatan ataupun tantangan akademis sehariharinya di sekolah, atau yang di sebut memiliki kemampuan academic buoyancy.

Penelitian ini juga membuktikan bahwa academic buoyancy terbukti secara signifikan berkorelasi dengan engagement. Artinya temuan dalam penelitian ini juga membuktikan bahwa hipotesis keempat yang diajukan oleh peneliti dapat diterima. Hal ini juga memberikan bukti empiris terhadap kosep dari Martin dan Marsh (2009) yang menyatakan bahwa siswa yang memiliki academic buoyancy akan engage dengan aktivitas belajarnya di kelas. Dan juga sesuai dengan penelitian terdahulu yang menunjukkan bahwa siswa dengan academic buoyancy yang tinggi, memiliki level engagement yang tinggi pula (Martin, 2014; Martin et al. 2010, Martin \& Marsh 2006; 2008; Putwain et al. 2012).1

Hasil penelitian ini memberikan dukungan mengenai pentingnya Teacher structure dalam membentuk kemampuan siswa SMA dalam mengatasi masalah-masalah akademis sehari-hari di sekolah (academic buoyancy), dan nantinya membuat siswa menjadi engage terhadap aktivitas belajarnya di kelas. Terutama pada siswa SMA, dimana pada jenjang pendidikan ini sebagian besar siswa mengalami peningkatan dalam hal tantangan serta meningkatnya kecemasan siswa dalam bidang akademik (Wang, Chow, Hofkens and Aro 
2015). Selanjutnya kondisi ini akan berdampak terhadap penurunan engagement di jenjang pendidikan sekolah menengah (Eccles,1993).

\section{Kesimpulan}

Secara keseluruhan dapat disimpulkan bahwa perilaku engagement siswa terhadap aktivitas belajar di kelas tergantung dari teacher structure yang diterima siswa dan kemampuan siswa mengatasi masalah akademis sehari-hari di sekolah. Secara metodologi penelitian ini terbatas dilakukan pada satu SMA saja dengan jumlah responden sebanyak 213 siswa. Dengan jumlah responden yang terbatas ini, perlu dilakukan penelitian lanjutan dengan cakupan lokasi yang lebih luas sehingga diperoleh hasil penelitian yang dapat diaplikasikan pada populasi yang luas. Selain dari teacher structure, hasil kajian literatur mengidentifikasikan bahwa dimensi lain dari dukungan guru yaitu autonomy support, involvement dapat memengaruhi kemampuan academic buoyancy dan selanjutnya mempengaruhi engagement terhadap aktivitas belajar di kelas. Oleh karena itu terbuka peluang bagi dilakukanya penelitian yang menguji dimensi dukungan guru lainnya terhadap academic buoyancy maupun pada engagement dan educational outcomes lain pada siswa sekolah menengah atas.

Saran

Saran yang dapat diberikan berdasarkan temuan ini bahwa guru perlu menyadari bahwa setiap siswa memerlukan kemampuan untuk mengatasi masalah akademis sehari-hari di sekolah untuk tetap terlibat dengan aktivitas akademis di kelas dan hal ini dapat dipenuhi salah satunya oleh adanya dukungan guru berupa teacher structure.

\section{Referensi}

Appleton, J. J., Christenson, S. L., \& Furlong, M. J. (2008). Student engagement with school: Critical conceptual and methodological issues of the construct. Psychology in the Schools. 45(5):369 - 386. DOI: 10.1002/pits.20303

Connell, James P, \& James G Wellborn. (1991). Competence, Autonomy, and Relatedness: A Motivational Analysis of Self-system Processes. In Self processes and development.The Minnesota symposia on child psychology, Vol. 23. Self processes and development (pp. 43-77). Hillsdale, NJ, US: Lawrence Erlbaum Associates, Inc.

Fredricks, J. A., Blumenfeld, P. C., \& Paris, A. H. (2004). School Engagement: Potential of the Concept, State of the Evidence. Review of Educational Research, 74(1), 59-109. doi: 


\subsection{2/00346543074001059}

Grolnick, W. M., \& Ryan, R. (1990). Self-perception, motivations, and adjustment in children with learning disabilities:a multiple group comparison study. Journal of Learning Disabilities. doi: 10.3102/00346543074001059

Jang, H., Reeve, J., \& Deci, E. L. (2010). Engaging Students in Learning Activities: It is Not Autonomy Support or Structure but Autonomy Support and Structure. Journal of Educational Psychology, 102(3):588-600. doi: 10.1037/a0019682

La Guardia, J. G., Ryan, R. M., Couchman, C. E., \& Deci, E. L. (2000). Within-Person Variation in Security of Attachment. Journal of Personality and Social Psychology. 79(3), 367-384.

Martin, A. J. (2013). Academic buoyancy and academic resilience: Exploring "everyday" and "classic" resilience in the face of academic adversity. School Psychology International, 34(5), 488-500.

Martin, A. J. (2014). Academic buoyancy and academic outcomes: Towards a further understanding of students with attention-deficit/hyperactivity disorder (ADHD), students without ADHD, and academic buoyancy itself. British Journal of Educational Psychology, Vol. 84, pp. 86-107.

Martin, A. J., Colmar, S. H., Davey, L. A., \& Marsh, H. W. (2010). Longitudinal modelling of academic buoyancy and motivation: Do the "5Cs" hold up over time? British Journal of Educational Psychology, 80(3), 473-496.

Martin, A. J., Ginns, P., Brackett, M. A., Malmberg, L. E., \& Hall, J. (2013). Academic buoyancy and psychological risk: Exploring reciprocal relationships. Learning and Individual Differences, 27, 128-133.

Martin, A. J., \& Marsh, H. W. (2006). Academic Resilience and Its Psychological and Educational Correlates: a Construct Validity Approach. 43(3). Retrieved from www.interscience.wiley.com

Martin, A. J., \& Marsh, H. W. (2008a). Academic buoyancy: Towards an understanding of students' everyday academic resilience. Journal of School Psychology.

Martin, A. J., \& Marsh, H. W. (2008b). Academic buoyancy: Towards an understanding of students' everyday academic resilience. Journal of School Psychology, Vol. 46, pp. 53-83.

Reeve, J., \& Jang, H. (2006). What teachers say and do to support students' autonomy during a learning activity. Journal of Educational Psychology, 3, 367-384.

Ryan R.M dan Decy E.L. (2000). Self-determination theory and the facilitatiton of intrinsic motivation, social development, and well-being. American Psychological Association.

Skinner, E. A., \& Belmont, M. J. (1993). Motivation in the Classroom: Reciprocal Effects of Teacher Behavior and Student Engagement Across the School Year. Journal of Educational Psychology, 85. H. 571-581.

Skinner, E. A., \& Pitzer, J. R. (2012a). Developmental dynamics of student engagement, coping, and everyday resilience. In S.L.Christenson, A.L.Reschly, \& C. Wylie (Eds.), Handbook of Research on Student Engagement. (pp.21-44). New York: Spinger Science.

Skinner, E. A., \& Pitzer, J. R. (2012b). Handbook of Research on Student Engagement. 21-44. Newyork, NY : Springer Science. 